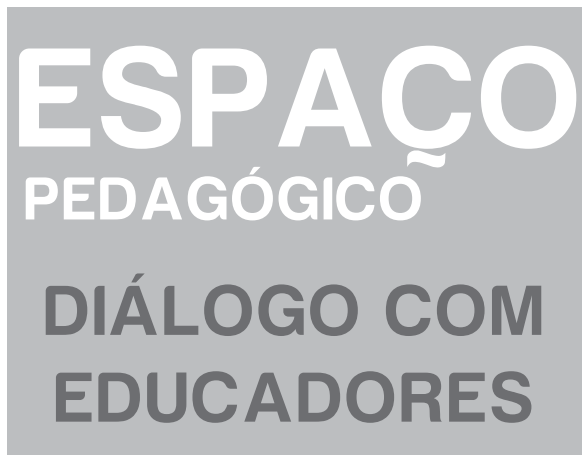





\section{Diálogo com Educadores ${ }^{1}$}

\section{Prof. Dr. Bruno Pucci}

O entrevistado desta edição da Revista Espaço Pedagógico, Professor Doutor Bruno Pucci, aposentado da Universidade Federal de São Carlos (1996), é, atualmente, professor titular da Universidade Metodista de Piracicaba. Tem experiência na área de Educação, notadamente em Filosofia da Educação, atuando principalmente nos seguintes temas: teoria crítica e educação, estética e educação, novas tecnologias e educação, filosofia da educação e educação. É autor de vasta publicação bibliográfica, destacando-se livros e ensaios, e, além disso, possui longa trajetória de orientação, sendo responsável pela formação de várias gerações de docentes pesquisadores.

EP: Prezado Prof. Bruno Pucci, é com muita satisfação que iniciamos essa entrevista perguntando-lhe onde nasceu, como foi sua infância, qual era o contexto sociocultural, político e religioso.

Pucci: Nasci em Marília, interior do estado de São Paulo (Alta Paulista), em 1940, na Vila São Miguel. Marília, distante da capital $443 \mathrm{~km}$ por rodovia, na ocasião, tinha apenas 11 anos de fundação. Meu pai, imigrante italiano, chegara ao Brasil com 19 anos, em 1911, pouco antes da Grande Guerra, e, depois de trabalhar como colono em diversas fazendas de café, pelo interior do estado, foi parar em minha cidade natal e lá, como operário de uma indústria média, conheceu minha mãe, neta de portugueses, analfabeta, embora filha de um educador. Aprendi a escrever com meu avô materno. Família religiosa, conservadora, missa todos os domingos, educação severa, transgressões corrigidas com palmatória. Lembro-me de como meu pai vibrou com a vitória de Getúlio Vargas, em 1950, como Presidente do Brasil. Minha mãe, dona de casa, pessoa simples, humilde, acolhedora, teve seis filhos; sobreviveram três. Eu fui o primeiro dos sobreviventes. Estudava no Grupo Escolar de Marília, em meu terceiro ano escolar, quando fui convidado para ingressar no Seminário dos Estigmatinos, uma congregação religiosa italiana no Brasil. Achei interessante a ideia, tive apoio de meus pais. Com 10 anos, em 1951, ingressei no Seminário Menor dos Estigmatinos, em Rio Claro, SP. Naquele tempo, era uma festa ir de Marília a Rio Claro pelo trem azul da Companhia Paulista de Estradas de Ferro. Eu já era torcedor do Corinthians.

http://dx.doi.org/10.5335/rep.v21i1.3880 
EP: Que experiências pedagógicas e que perfil de professor mais lhe marcaram?

Pucci: No Seminário de Menores dos Estigmatinos em Rio Claro, SP cursei o ginasial e completei-o em Ribeirão Preto, SP, onde realizei, também, os estudos do colegial. Fiz um ano de noviciado - preparação para assumir os votos religiosos de pobreza, castidade e obediência - em Casa Branca, SP. Retornei a Ribeirão Preto e lá cursei a graduação em Filosofia; conclui-a em Campinas, SP e ingressei no curso de Teologia. Em 1965, com 25 anos, fui ordenado sacerdote e encaminhado a Roma, Itália, para completar os estudos de Teologia e obter a licenciatura nessa área de conhecimento. A Universidade que me acolheu, nos anos 1965/1966, foi o Angelicum, dos dominicanos. Frequentei, nos dois anos seguintes, o curso de Pós-Graduação em Teologia Moral junto aos Redentoristas, no Alphonsianum, na Via Merulana, pertinho da Basílica de Santa Maria Maior. Saí da Congregação dos Estigmatinos e, também, da vida sacerdotal em 1970, com 30 anos de idade. Para sobreviver fora do seminário e manter minhas aulas de língua portuguesa na pequenina Corumbataí, SP, fiz o curso de graduação em Letras na Universidade Metodista de Piracicaba (Unimep), que, em 1972, ainda não era universidade. Na Unimep, realizei, também, meu curso de mestrado em Educação, de 1972 a 1976. O mestrado na Unimep foi o primeiro curso de pós-graduação em Educação do interior do Estado de São Paulo. Fui aluno da primeira turma e o terceiro a defender a dissertação nesse programa. Em 1978, ingressei na primeira turma do doutorado em Educação da PUC-SP, defendendo minha tese no primeiro semestre de 1982. Fiz um relato global de minha participação como aluno/aprendiz para poder responder à questão acima posta e à questão que vem a seguir. Nesta, restringir-me-ei às experiências formativas dos ensinos fundamental e médio, particularmente no período que vivi no Seminário Menor. Se não tivesse ingressado no seminário, eu não teria continuado minha formação escolar. Sou eternamente grato a todos aqueles que me ajudaram a permanecer nesse ambiente formativo durante vinte anos de minha vida. Lá eu aprendi a estudar, a conhecer outras línguas - latim, grego, francês, italiano -, a procurar com respeito e persistência meu lugar - na tensão com outros garotos de minha idade -, a superar os problemas da adolescência não obstante algumas deficiências educativas -, a desenvolver o gosto pela arte, particularmente pela música e pela literatura, a praticar o esporte em um clima de competição e, ao mesmo tempo, de irmandade, a ser uma pessoa disciplinada. Não tenho recordação específica de nenhum professor que, nesse período, tenha me chamado a atenção pelo seu saber ou pela sua didática. Recordo-me, sim, dos padres que acompanhavam os seminaristas em todos os momentos de seu cotidiano. Tinham eles o cognome de "padres prefeitos". Eles foram meus grandes educadores, pela presença vigilante, pelos incentivos, pelas punições, pela paternidade. 
EP: O que mais o marcou em sua experiência formativa no curso de graduação?

Pucci: Como já expus, cursei três graduações: Filosofia, Teologia e Letras. As duas primeiras, como seminarista maior, após já ter me comprometido com os votos religiosos. Meu curso de Filosofia foi realizado em dois anos, no seminário (19591960), e, posteriormente, complementado por mais um ano com as disciplinas pedagógicas em uma universidade particular, a Organização Mogiana de Estudos e Cultura (OMEC), de Mogi das Cruzes, em 1970. Ressalto os dois anos intensos de estudos filosóficos; aulas pela manhã; estudos e exercícios à tarde e até à noite. A orientação filosófica predominante foi a aristotélica, em sua versão escolástica. Nas disciplinas da História da Filosofia, chegamos até Hegel; o materialismo histórico, a fenomenologia, os existencialistas só os estudei posteriormente. Lembro-me de um curso de férias de Filosofia que realizei em Marília, em 1961, organizado pelo governo federal, de nome Campanha de Aperfeiçoamento e Difusão do Ensino Secundário (CADES), que conferia aos aprovados o registro de professor do ensino secundário e o direito de lecionar onde não houvesse licenciados por faculdade; por ocasião da avaliação do curso, o professor de Filosofia me perguntou: o que você sabe sobre Descartes e sobre Sartre? Eu lhe respondi: sobre Descartes estou pronto para lhe responder as questões. Sobre Sartre, vou ter que estudá-lo, pois meu curso não me ofereceu essa possibilidade. Foram cinco os anos dedicados aos estudos da Teologia, quatro no Seminário Maior, em Campinas, SP, e um em Roma. A orientação teórico-metodológica dominante também foi a escolástica, sob a direção de Tomás de Aquino. A maioria dos livros-textos era em latim. Lembro-me do exame final escrito da licenciatura em Teologia, no Angelicum, em que, durante quatro horas, expus minhas considerações escolasticamente na língua latina. Afinal, Angelicum é o nome honorífico atribuído a Tomás de Aquino, o primeiro de todos os escolásticos. Ainda hoje, conservo com carinho os nove volumes da Suma teológica, publicada pelas Edições Loyola, e lamento a falta de tempo para retomar a leitura dessa grandiosa obra do século XIII. O curso de pós-graduação que realizei a seguir, em Roma, junto ao Alphonsianum, foi um acontecimento marcante em minha vida pessoal e científica. Estávamos em 1966, logo após a realização do Concílio Vaticano II, cujos principais documentos sociais tinham sido guiados não mais pela escolástica, mas pela fenomenologia, inspirada no paleontólogo e jesuíta Teilhard de Chardin. Isso significava um avanço muito grande da Igreja Católica na atualização de sua teologia e de sua pastoral. E a maioria das disciplinas ministradas no Alphonsianum tinha como referencial a fenomenologia. Comecei a respirar ares novos e fecundos, que, na tensão com os ensinamentos escolásticos, potenciaram-me ainda mais a vontade de estudar e de apreender. Voltando ao Brasil, em maio de 1968, meus superiores enviaram-me ao Rio de Janeiro para realizar 
um curso de Teologia Pastoral. Achavam eles que eu estava ainda imaturo para lecionar as disciplinas filosóficas ou teológicas no Seminário Maior, objetivo para o qual haviam me enviado a Roma. Esse estágio de aperfeiçoamento no Colégio do Sión, perto do Cristo Redentor, foi outro acontecimento importante em minha experiência científica. Se em Roma eu tinha me aproximado da fenomenologia, mesmo que sob seu viés cristão, no Rio me aproximei da teologia da libertação. A maioria das disciplinas ali oferecidas tinha como referencial teórico o materialismo histórico, entendido como método fecundo de análise dos problemas sociais do mundo contemporâneo. Nesses últimos três anos (1966-1968), iniciei um processo de abertura, de modificação em meu modo de pensar, de sentir, de agir, que me influencia até os dias de hoje. De certa maneira, com forte bagagem escolástica, deixei-me conduzir pela fecunda inspiração fenomenológica e abri caminhos alternativos para os problemas e questões sociais trazidos pelo materialismo histórico. Poderia, sim, aqui destacar alguns educadores fundamentais em meu processo formativo nesse período universitário, como, por exemplo, o Pe. Modesto Nunes, estigmatino, conhecedor profundo e atualizado das questões teológicas vividas pela igreja nos inícios dos anos sessenta; o dominicano Lumbreras, espanhol, que, com seus 70 anos, entusiasmava-se e entusiasmava-nos com os ensinamentos escolásticos morais, no Angelicum; Bernad Hering, um dos grandes teólogos do Vaticano II, autor de uma nova proposta de teologia moral e professor no Alphonsianum; Hugo Assmann, um dos iniciantes da teologia da libertação na América Latina e professor no curso de Pastoral Litúrgica do Rio de Janeiro. Mas prefiro considerar como o grande educador, como o que mais modelou minha individualidade, até então, o coletivo, o conjunto das experiências formativas, as múltiplas determinações que propiciaram esses ambientes de aprendizagem. E, posteriormente, após deixar o sacerdócio, por circunstâncias da vida, fiz a graduação em Letras/Literatura, na Unimep, e a dimensão estética das obras de arte acompanham-me o tempo todo em minha docência e em minhas pesquisas. Foi na disciplina Cultura Brasileira, do curso de Letras, que tive a graça de conhecer Guimarães Rosa, ao fazer um trabalho de cunho interpretativo sobre o conto "A hora e a vez de Augusto Matraga".

EP: Como concebe a docência e o que considera significativo na experiência pedagógica de sala de aula?

Pucci: À semelhança de Paulo Freire, concebo a docência como o processo de ensinar e aprender. Para ensinar, tem-se que estudar, pesquisar, e muito. $\mathrm{E}$ à medida que se ensina, através do diálogo, ao mesmo tempo se aprende. Como afirma Guimarães Rosa, "mestre não é quem sempre ensina mas quem de repente aprende". Então, para ser docente, é preciso ser um "eterno aprendiz"; a humildade 
e a sabedoria são as duas virtudes básicas de um docente. A humildade que o coloca muito próximo do discente, como alguém que precisa do outro para ser o que é, mestre. A sabedoria, resultante das experiências formativas acumuladas da vida, que o leva a ser prudente, atencioso, enérgico quando for necessário, amigo e, por vezes, confidente. Tempos atrás, escrevi uma crônica que foi publicada na Revista Comunicações, do PPGE/Unimep (2000, p. 223), com o título "Professor, profissão professar", que expressa bem minha concepção de docência e do que considero significativo na experiência pedagógica de sala de aula. Permitam-me apresentar-lhes alguns fragmentos:

"Professor [...]. Aquele que está sempre envolvido por livros, ideias, escritos, e, de tanto lê-los, ouvi-los, apalpá-los, acaba se tornando um mensageiro ambulante dos vates, dos filósofos, dos homens da vida. Sua experiência se constrói na experiência de outros, dos sábios, dos que têm o saber e o sabor da vida, dos que enxergam o mundo por um olhar novo, esquisito, despretensioso, que causa espanto, ternura, compaixão. [...]. Ser professor, estar carregado de um campo de forças intenso, potente, e expressar essa tensão nas palavras, nos escritos, no olhar, nos acontecimentos da vida, fazendo com que sua chama incendeie corpos e almas sedentos de ser. Ser professor, ser sensível às pessoas, ouvi-las, deixá-las se desnudar, sem pejo, não ter nada a lhes oferecer, a não ser a atenção, o silêncio; e, ao mesmo tempo, ser-lhes exigente, brutalmente sincero, fazê-las ousar, ir além de si mesmas, transcender as situações impossíveis. Ouvir os outros e transmitir-lhes desejos, mesmo quando seu coração está sendo consumido pelas amarguras do cotidiano, e seus dias sangrando pelas dores do existir. Porque ele nada tem, muito pode oferecer, mas nada de importante, de seguro, de tranquilo, de útil. Ser professor é ser anacrônico no seu tempo, que valoriza exclusivamente o que gera trocas, haveres, posses. Mas é ser, ao mesmo tempo, extemporâneo de seus dias pela crença teimosa no retorno da luz e da canção. Aquele que é vilmente pago para ensinar, que "ensina generalidades"; que castiga, disciplina e tem o poder da nota e da promoção; que anota, relata e marca a vida dos que em suas mãos estão. Aquele que com-vive, que aparenta força e decisão, que espera muito ser ainda alguém na vida. Ser professor, ser mestre: aquele que ensina, aquele que mais aprende que ensina, que presta atenção no desabrochar do outro, e cresce com ele e se sente realizado quando um aluno ouve seus problemas e lhe dá a mão para que a caminhada continue. Ser professor, adotar, abraçar, seguir uma causa, mesmo que sua realização impertinente produza danos pessoais e crises consistentes. [...]. Professor, profissão professar".

EP: Como essas experiências influenciaram suas investigações posteriores e atuais? 
Pucci: Para responder a essa questão, preciso ainda terminar o relato de outras influências teóricas marcantes em minha formação. Já falei da escolástica, da fenomenologia e do materialismo histórico, em tempos de seminário. Mas depois que deixei o sacerdócio e "caí na vida", outras experiências formativas mostraram-se decisivas em minha vida profissional. Em 1976, defendi a dissertação de mestrado no PPGE/Unimep, analisando, com a ajuda do referencial fenomenológico, o ensino da disciplina "Expressão e Comunicação" para alunos da $5^{\mathrm{a}}$ a $8^{\mathrm{a}}$ série do ensino fundamental. A dissertação intitulou-se "Por uma práxis educacional da Comunicação e Expressão". Meus mestres nas disciplinas foram Geraldo Tonaco (também orientador), Antônio Joaquim Severino, Demerval Saviani e Aquiles Von Zuben. O referencial teórico predominante nessa experiência formativa foi a fenomenologia de Gusdorf, Merleau-Ponty, Ricoeur, Van Riet e outros. Lembro-me do primeiro seminário em que fui incumbido de apresentar e analisar, sob a orientação de Von Zuben, o "Prefácio" do livro Fenomenologia da percepção, de Merleau-Ponty. Tive que dispender muito tempo e leituras para dar conta desse trabalho. Mas valeu a pena pelo aprendizado e pela experiência formativa. Ainda hoje, na disciplina "Epistemologia e Educação I", do doutorado em Educação, sob minha responsabilidade, quando abordamos os conceitos básicos que constituem a fenomenologia, o texto de apoio e de análise é o "Prefácio" da Fenomenologia da percepção. E abordo-o com entusiasmo e dedicação, como se estivesse em 1972, nas aulas de Von Zuben. Em 1978, ingressei no doutorado em Educação na PUC-SP. Meus mestres eram os mesmos que me acompanharam no mestrado: Geraldo Tonaco, Antônio Joaquim Severino, Demerval Saviani. Meu orientador foi José Luiz Sigrist, que, naquele tempo, era coordenador do PPGE/Unimep. Meus colegas de turma eram pesquisadores de renome na área da Educação: Antônio Chizzotti, Mirian Warde, Luiz Antônio Cunha, Paulo Nosella, Beth de Oliveira, Osmar Fávero, Carlos Jamil Cury, Neidson Rodrigues, Guiomar Namo de Mello. Sentia-me lisonjeado no entremeio de colegas competentes e solidários. Pena que o Neidson já nos deixou. Sinto muito sua falta! Minha tese, "A nova práxis educacional da Igreja - 1968-1979" foi uma análise da atuação política da Igreja Católica em defesa dos direitos humanos no período do golpe militar de 1964 e, também, das Comunidades Eclesiais de Base junto aos pobres e às periferias da cidade. $\mathrm{E}$ teve como referencial teórico as categorias da Filosofia da Práxis, de Antonio Gramsci. Como se vê, em 1982, minha opção filosófica já era fundamentalmente materialista histórica. E por esses caminhos continuei até 1991, quando, então, na UFSCar, como professor e orientador de mestrandos e doutorandos em Educação, fui surpreendido pela Teoria Crítica da Sociedade, particularmente por Theodor Adorno, até os dias de hoje, referência de minhas pesquisas filosófico-educacionais. A vinculação com a 
Filosofia da Práxis de Gramsci em minha experiência formativa levou-me, no início dos anos 80, a participar da fundação do Partido dos Trabalhadores. Não era possível eu continuar um estudioso de Gramsci e não me envolver em uma práxis política naquele momento histórico. E durante uma década fui um intelectual orgânico, militante do PT; cheguei até a candidatar-me a prefeito da cidade de Rio Claro, SP, em 1982, mas, no final dos anos 1980, abandonei a militância partidária por entender que o meu trabalho político era mesmo no interior da academia. Foi quando, em 1990, fui procurado por três mestrandos e um doutorando do PPGE/ UFSCar - tinha ingressado nesse Programa em 1986 -, que queriam ser meus orientados, e, ao mesmo tempo, ter, como referencial teórico de suas pesquisas, as reflexões filosóficas de Theodor Adorno. Foi quando, então, como um gramsciano convicto, comecei a ler Theodor Adorno. Foi uma experiência dolorosa, no início. Tentei em outra crônica acadêmica expressar esse sentimento. Cito um fragmento:

"No início esse pensador inspirava suspeita e rejeição. Ele não aceitava o proletariado como o sujeito revolucionário da história e criticava acintosamente todos os que se utilizavam da filosofia como instrumento primeiro para transformar a realidade. A maneira de expor suas ideias era fragmentária, rebuscada, hermética. Para se entender um texto seu era preciso mais de uma leitura, esforço redobrado e coletivo. Era tido por alguns como materialista histórico, mas enraizava em seu pensamento autores sombrios e excêntricos, como Nietzsche e Freud, se servia amiúde do "positivista" Weber e navegava fluentemente nas categorias idealistas de Kant e de Hegel. Que com-fusão! [...]. No entanto, com o decorrer das leituras e dos encontros, os persistentes leitores do grupo se sentiram progressivamente atraídos por esse pensador, difícil de ser devorado. A sua maneira de compor frases, de mexer com a ambiguidade das palavras, de extrair de conceitos expressões inusitadas, produzia uma sensação de prazer, fazia bem à alma. [...]. Certa vez, ele disse que as coisas têm sua história e que para conhecê-las bem é preciso fitá-las tão longamente até que elas, constrangidas, acabem dizendo o que são. E continuou a fazer afirmações absurdas como esta: 'Para o intelectual, a solidão inviolável é a única forma em que ele ainda é capaz de dar provas de solidariedade" (Comunicações, PPGE/UNIMEP, 2001, p. 165).

EP: $O$ que é mais relevante na formação de novos pesquisadores? Qual é sua reflexão sobre a dicotomia que tem se estabelecido, principalmente nas últimas décadas, entre pesquisa e ensino?

Pucci: Vou responder a essas duas questões ao mesmo tempo, pois que se complementam. Há mais de um aspecto relevante na formação de novos pesquisadores. Começo pelos cursos de graduação, que deveriam, sejam eles públicos ou 
privados, diurnos ou noturnos, presenciais ou a distância, transformar-se em espaços formadores de um profissional específico e, também, de um pesquisador da área. Daí a necessidade de as disciplinas serem ministradas mediante a exposição das temáticas a elas referentes e, também, pelos ensinamentos e exercícios de investigação científica. Despertar no graduando o interesse e o gosto pela busca do conhecimento, pela descoberta de coisas novas. Nessa perspectiva, ensinar a fazer pesquisa não seria tarefa apenas das disciplinas metodológicas que preparam a elaboração da monografia final do curso. As disciplinas da graduação, todas, deveriam propiciar aos formandos exercícios de reflexão, de análise, de interpretação, de iniciação à produção científica. Não são suficientes os elementos técnicos da investigação; é preciso, além disso, formar o espírito crítico e autônomo do novo pesquisador. Para que isso aconteça, é fundamental que os docentes da graduação sejam também pesquisadores críticos, porque ninguém dá o que não tem. Outro elemento importante é a criação de grupos de pesquisas e a participação dos alunos da graduação nos projetos de pesquisa dos docentes. Esse item é uma das exigências da avaliação trienal da pós-graduação realizada pela Capes. Propiciar aos graduandos sua participação efetiva em um projeto de investigação, particularmente por meio de bolsas de iniciação científica, é uma forma de colaboração extraordinária na constituição de novos pesquisadores. Penso que, se o curso de graduação contribuir mais no ensino e no exercício da pesquisa, se o docente da graduação tiver também condições de desenvolver pesquisas científicas e expor seus resultados em eventos, se o aluno da graduação participar ativamente de um projeto de pesquisa conduzido pelo docente, teremos desenvolvido um ambiente formativo não só de novos pesquisadores, como também de novos docentes. Não há docência sem pesquisa. $\mathrm{O}$ docente que não pesquisa debilita-se. $\mathrm{O}$ aluno que pesquisa enxerga longe.

EP: É possível conciliar formação de pesquisadores com a redução do tempo de estudos?

Pucci: No contexto da reflexão acima, em que os cursos de graduação deveriam empenhar-se mais em formar o profissional e também o pesquisador, não é possível reduzir o tempo de estudos. A aprendizagem e os exercícios de investigação, a construção da experiência formativa de pesquisador, seu amadurecimento, tudo isso exige mais tempo e dedicação. A redução do prazo de mestrado para 24 meses, que é o tempo das bolsas das agências de fomento, de certa maneira, enfraqueceu os programas de pós-graduação. Tomo a estrutura curricular da Unimep como exemplo de análise: um pós-graduando, para integralizar o mestrado, deve cursar duas disciplinas obrigatórias, três disciplinas optativas, três disciplinas de pesquisa (Seminários de Pesquisa) junto a seu Núcleo de Estudos e Pesquisa, desenvolver 
atividades supervisionadas vinculadas à sua pesquisa (apresentação de trabalhos em eventos científicos, minicursos, conferências, confecção de artigos, entre outras) num total de quatro créditos e, obviamente, escrever sua dissertação de mestrado, participar do exame de qualificação e defendê-la publicamente. Não se exige de uma dissertação de mestrado originalidade, mas sim que ela seja um trabalho científico bem estruturado, em que os elementos teórico-metodológicos sejam expostos com clareza, correção e coerência. E o projeto de pesquisa de um mestrando, particularmente em uma universidade confessional como a Unimep, em muitos casos, é a primeira experiência séria de uma investigação científica. Pois bem, a partir do ano de 1999, o tempo de bolsa concedido pelas Agências de Apoio reduziu-se a 24 meses. E o mestrando passa, realmente, os primeiros doze meses e parte dos outros seis meses cursando disciplinas, robustecendo-se teórica e metodologicamente. É possível se fazer um trabalho teoricamente sério, bem fundamentado, que traga alguma contribuição para a ciência nessas condições? Antes de 1999, o mestrando tinha mais tempo para amadurecer, pesquisar e expor sua dissertação científica.

EP: Como analisa a pós-graduação brasileira, especialmente na educação e áreas afins?

Pucci: A pós-graduação brasileira, sistematizada e avaliada desde os anos 70 do século passado, é o lócus privilegiado da produção e da socialização científica em nosso país. Organizada como sistema no contexto do governo militar e da integração do país no capitalismo internacional, apoiada por verbas provindas de diferentes agências de fomento à pesquisa, governamentais ou não, desenvolveu-se de maneira sólida, progressiva e, nos dias de hoje, é referência nacional e internacional de produção científica de qualidade e de desenvolvimento de tecnologias voltadas ao desenvolvimento socioeconômico e cultural do país. Houve um aumento quantitativo e qualitativamente substancioso de artigos científicos, de livros, de capítulos de livros, resultantes de dissertações e teses defendidas nos programas de pós-graduação, de projetos de investigação científica desenvolvidos por doutores pesquisadores vinculados a programas de pós-graduação. A área da Educação, vinculada às Ciências Humanas e Sociais, é apenas uma das 48 áreas científicas avaliadas pela Capes. E hoje já são cerca de 120 programas de pós-graduação em Educação, cujos docentes e discentes desenvolvem investigações científicas sobre os problemas educacionais em nosso país. $\mathrm{E}$ a avaliação trienal da Capes - feita por nossos colegas pesquisadores sobre a coerência, consistência e abrangência da proposta do programa; sobre o corpo docente, sua constituição, suas pesquisas e produção científica; sobre o corpo discente e a produção de dissertações e teses; sobre a inserção regional e nacional do programa e sobre a integração com outros programas com 
vistas ao desenvolvimento da pesquisa e da pós-graduação e cooperação - são garantia de qualidade e de crescimento daquilo que é próprio da pós-graduação: formar pesquisadores. Ao mesmo tempo, o aumento significativo de revistas na área educacional, bem como de livros, de capítulos de livros, de organização de eventos científicos denota a fecundidade científica de nossa área e a necessidade de que os produtos sejam socializados, discutidos, criticados. Destaco, ainda, o crescente e insistente desafio da internacionalização da pesquisa, sonho e objetivo de todos os programas de pós-graduação em desenvolvimento. As parcerias com docentes de outros países, a presença ativa de pesquisadores visitantes, as exposições e debates de comunicações científicas em eventos internacionais fazem muito bem aos docentes pesquisadores e, também, a seus programas. Esses são alguns dos elementos positivos alcançados pela pós-graduação brasileira. Podemos, na análise da pós-graduação no Brasil, encontrar, também, uma série de problemas que estão sendo realçados e que precisam ser enfrentados. Vou citar alguns deles: o produtivismo acadêmico que atinge os docentes e os discentes da pós-graduação e a consequente falta de tempo para o bom desenvolvimento das pesquisas, para o amadurecimento da produção científica e a sua divulgação; a predominância das áreas das ciências naturais, biológicas e tecnológicas sobre as áreas das ciências humanas e sociais na recepção do apoio científico e das verbas de pesquisa, bem como no estabelecimento de critérios e valores para a avaliação científica e socialização dos produtos de pesquisa. Mas, na análise do conjunto, os programas de pós-graduação gozam de prestígio nacional e internacional e respondem satisfatoriamente ao apoio que têm recebido do governo e dos setores produtivos da sociedade.

\section{EP: O que considera nuclear na inserção social da pesquisa e da pós-graduação?}

Pucci: Nos últimos anos, tem crescido o empenho da Capes na atuação junto à educação básica. Essa instituição, que foi criada para atender especificamente a educação superior, agora se volta, também, para a educação básica e para a educação a distância. E a orientação da pesquisa e da pós-graduação na formação continuada dos docentes da educação básica tornou-se, praticamente, uma das exigências da Capes na avaliação trienal dos programas de pós-graduação, em especial na área da Educação. A criação do mestrado profissional, bem como o incentivo para que essa nova modalidade de mestrado se amplie, tem todo o apoio dessa instituição governamental. Eu tendo a concordar com a Capes no propósito de os programas de pós-graduação terem sempre diante de si essa responsabilidade social de, em seus projetos de pesquisa e de extensão, bem como na constituição de seus núcleos e/ou linhas de pesquisas, preocuparem-se, de maneira séria e competente, com a inserção social na região em que estão estabelecidos, investigando, analisando e 
propondo alternativas aos problemas educacionais das escolas de formação fundamental e média. Mas não só, pois os problemas educacionais vão muito além dos gerados no contexto da educação básica. Ao mesmo tempo, julgo que um programa de pós-graduação em educação, pela diversidade da formação de seu corpo docente, pelo leque de problemas educacionais a serem enfrentados nos projetos de pesquisa dos docentes e dos discentes, só terá condições de inserir-se socialmente e de modo fecundo em sua região se desenvolver parcerias de pesquisa, de estágios de pós-doutorado e de cooperação científica com outras IES nacionais e internacionais. É na tensão entre o regional e o nacional/internacional que um programa cresce, se desenvolve e se integra na sociedade local e brasileira na perspectiva de ajudar a solucionar os problemas educacionais.

\section{EP: É possível identificar um fio condutor em sua produção intelectual?}

Pucci: Como já afirmei anteriormente, cursei três graduações em minha formação básica no ensino superior: Filosofia, Teologia e Letras. E as três deram-se por circunstâncias da vida: porque estava no Seminário e queria me tornar sacerdote, era preciso cursar Filosofia e Teologia. Depois, quando deixei a vida religiosa e sacerdotal, lecionava em uma pequena escola a disciplina Comunicação e Expressão, tendo como apoio legal um registro da Cades, e, com medo de algum licenciado em Letras raptar minhas aulas, fiz o curso de Letras. A vida levou-me a essas três áreas do conhecimento. E posso afirmar, com o coração aberto, que gostei de ter despendido 11 anos de minha vida no convívio com essas áreas de conhecimento. Mas as circunstâncias, depois, me levaram para outra área, a Educação, que, desde 1972, conduz minhas pesquisas, estudos, produção e vida. Nessa área fiz o mestrado (1976) e o doutorado (1982). Contudo, as influências e as contribuições das outras três áreas fazem-se manifestar, de maneira clara e distinta, em minhas produções científicas, particularmente da Filosofia, que foi o caminho por meio do qual me aproximei da Educação. Desde os anos 1972, quando ingressei no mestrado em Educação na Unimep, são as correntes epistemológicas da Filosofia que iluminam meus passos como docente e pesquisador da Educação. Daí eu ser um membro do GT 17 da ANPEd e um de seus fundadores. Mas também, como afirmei anteriormente, as minhas fundamentações filosóficas foram variando e acontecendo pelas circunstâncias da vida acadêmica. O seminário fez de mim um escolástico (1959-1966); a pós-graduação em Teologia Moral fascinou-me com a fenomenologia (1967-1968), corrente que me acompanhou solidariamente no mestrado em Educação (1972-1976); já tinha experimentado, no curso de Teologia Pastoral do Rio de Janeiro (1968), e, depois, em uma disciplina que cursara com o prof. Claudio Barrighelli (1977), as propostas sedutoras do materialismo histórico, mas foi no curso de 
doutorado (1978-1982) que essa teoria me fez seu súdito e que eu a acompanhei, de forma militante, até os anos 1990, quando, então, fui atropelado pela teoria crítica da sociedade. De um lado, foram mesmo as correntes filosóficas que me atraíram e que atravessaram meu caminho e, de outro, quando estava ao lado delas e sustentado por elas, nunca as traí, fui sempre um seguidor convicto e defensor da causa. Então, se eu pudesse identificar um fio condutor em minha produção científica, eu diria que foi a minha paixão pela Sofia.

EP: De toda a sua produção intelectual, o que mais gosta e o que considera mais relevante? Por quê?

Pucci: Gosto mais de meus escritos que foram fundamentados na teoria crítica da sociedade, particularmente nos conceitos filosóficos e estéticos de Theodor Adorno; portanto, textos produzidos a partir de 1991. Se fosse fazer uma sistematização lógica de minha produção científica nesse período, diria que, nesses 22 anos, escrevi textos e ensaios sobre três perspectivas filosófico-educacionais: a questão da formação; a experiência estética e sua contribuição à formação; as novas tecnologias e a educação. Os ensaios de que eu mais gosto e, também, que julgo os mais relevantes, são aqueles sobre a experiência estética e sua contribuição à formação. Posso citar seis desses ensaios:

1) O non-sens e a mútua dependência das personagens de Beckett em Fim de Partida. Artefilosofia (UFOP), v. 13, p. 132-146, 2012. Escrito em parceria com Gilberto B. Marcon.

2) Os anos de aprendizado de Wilhelm Meister e a questão da Bildung em Theodor Adorno. In: WERLANG, Julio Cesar; ROSIN, Nilva. (Orgs.). Theodor Adorno: diálogos filosóficos em educação, ética e estética. Passo Fundo, RS: Editora do IFIBE, 2011, p. 13-42.

3) Para Rosa com Adorno: a luta agônica da palavra e do conceito em busca do "quem" das coisas. Artefilosofia (UFOP), v. 8, p. 122-133, 2010.

4) Afinidades eletivas: os irmãos Taviani recriam Goethe. In: LOUREIRO, Robson; ZUIN, Antonio Álvaro Soares (Orgs.). A teoria crítica vai ao cinema. Vitória, ES: Ed. da Universidade Federal do Espírito Santo, 2010. v. 1. p. 177-204. Escrito em parceria com Josianne F. Cerasoli.

5) A alegoria da esperança no Doutor Fausto, a quatro mãos. In: ZUIN, A. A. S.; DURÃO, F. A.; VAZ, A. F. (Orgs.). Indústria cultural hoje. São Paulo: Boitempo, 2008. v. 1. p. 147-162.

6) Estética e Alteridade: Beckett, Adorno e a contemporaneidade. In: TREVISAN, Amarildo Luiz; TOMAZETTI, Elisete M. (Orgs.). Cultura e alteridade: confluências. Ijuí: Ed. Unijuí, 2006. p. 79-100. 
Um dia publicarei meus textos sobre a experiência estética em forma de uma coletânea.

EP: Do seu ponto de vista, quais são os temas e problemas de fronteira entre filosofia e educação?

Pucci: Diria que o campo fronteiriço entre filosofia e educação é abrangente e mais extenso do que pressupomos. Toda reflexão filosófica, enquanto um processo de análise, interpretação, crítica, busca do conhecimento, da verdade, é um conjunto de atitudes eminentemente formativas, pois é um processo que procura ir além do fenômeno, das aparências, que propicia a obtenção de uma perspectiva mais adequada e qualificada do problema, com consequências éticas favoráveis a uma ação educativa. Por sua vez, o processo formativo, na tensão entre a integração do indivíduo no mundo em que está vivendo e a busca de sua autonomia na luta contra o todo social que o quer subjugar, precisa o tempo todo da reflexão, da crítica, da interpretação da realidade. A educação só fará jus a seu conceito se for o tempo todo amiga da sabedoria. A filosofia da educação é apenas uma subárea da filosofia, e sua especificidade é analisar, refletir e criticar os problemas que assolam a educação. E ela desenvolve as atividades que lhe são próprias por meio das correntes epistemológicas mais sensíveis a iluminar as contradições que entremeiam as experiências formativas dos tempos presentes. Mas a filosofia faz-se necessária à educação não apenas sob o manto de uma subárea. A educação precisa da filosofia em todas as suas dimensões: enquanto processo de alfabetização de crianças, jovens e adultos; enquanto didática e técnicas de aprendizagem; enquanto constituição de um currículo de ensino; enquanto educação básica ou superior; ou seja, em todos os momentos. São duas irmãs gêmeas, a Sofia e a Paideia, esta, em outros tempos, também chamada de Humanitas ou de Bildung. Enquanto estiverem juntas, na tensão de suas especificidades, tanto a educação quanto a filosofia poderão trazer contribuições efetivas para a emancipação do indivíduo e da sociedade. Se separadas e/ou apenas aglutinadas funcionalmente, tanto na sociedade quanto na escola, predominará o homo prático, calculista, individualista.

\section{EP: Em que sentido a educação é um problema filosófico?}

Pucci: Vou tentar responder a essa questão com a ajuda de algumas ideias de Theodor Adorno, em sua conferência de 1931, quando ingressa como docente na Universidade de Frankfurt, intitulada "A atualidade da Filosofia". A primeira ideia é que a filosofia contemporânea, de um lado, deve abandonar a ilusão de que é possível, pela capacidade do pensamento, apoderar-se da totalidade do real mediante 
seus conceitos e teorias; de outro lado, que ela deve se voltar para o mutável e o efêmero, que também são dignos da filosofia. Uma segunda ideia é o entendimento da filosofia enquanto interpretação, e que seu eterno paradoxo é desenvolver um processo de interpretação, com pretensão à verdade, sem possuir nunca uma chave segura para fazê-lo, pois as figuras enigmáticas dos entes históricos, em seus admiráveis entrelaçamentos, fornecem apenas indícios fugazes e evanescentes do que são. E uma terceira ideia, a interpretação não coincide com a busca de um sentido que já se encontra pronto e permanente por detrás da questão, mas se volta para o desprovido de intenção, para iluminá-lo mediante a combinação de elementos analiticamente separados, reagrupando-os em uma nova configuração e construindo, assim, com a ajuda da fantasia exata, a chave de sua elucidação. Esse é, para Adorno, o programa de todo o autêntico conhecimento materialista e caracteriza a exigência de a filosofia dar resposta, a todo momento, às questões da realidade circundante. Nessa perspectiva, a educação, entendida não como um conceito abstrato, absoluto, e sim como um processo histórico, que se dá num tempo determinado e numa realidade específica, levanta uma série de questões, de problemas, no confronto dos elementos diversificados que a constituem, nas graduações de densidade de que necessita para atender a seus objetivos, problemas estes que não contam com conceitos prontos e acabados para iluminá-los e auxiliá-los na solução e que necessitam o tempo todo da interpretação filosófica. Então, a educação, não só enquanto um conceito genérico e histórico ao mesmo tempo, precisa da filosofia; mas também enquanto problemas do cotidiano, da periferia, da educação básica, da alfabetização dos jovens e adultos, precisam da interpretação, da busca de uma nova configuração, para que sejam iluminados, enfrentados. Não se trata de adequar os problemas do cotidiano escolar às malhas de nossas categorias epistemológicas preferidas, e sim de construir novas categorias que ajudem a iluminar mais e mais os problemas.

EP: Por onde passa a relevância de uma filosofia da educação na atualidade? Quais seriam suas tarefas? Quais são as dificuldades (epistemológicas e acadêmicas) para se solidificar como área do conhecimento?

Pucci: Penso que a relevância da filosofia da educação fica explícita nas análises feitas por mim como resposta às questões desta entrevista. Enquanto uma subárea auxiliar e, ao mesmo tempo, constitutiva da Educação, sua tarefa se cumpre quando coloca seus instrumentos de pesquisa e de interpretação - os conceitos e as teorias - na tensão dialética com os problemas educacionais, na busca de configurações fecundas para iluminá-los e apontar-lhes perspectivas de solução. A 
essa tarefa, os filósofos da educação têm dedicado majoritariamente sua atenção e atuação e proporcionado contribuições significativas. Enquanto parte constitutiva da Filosofia, essa subárea se encontra em processo de crescimento. De um lado, é vista com reserva e de forma marginal pelas subáreas históricas filosóficas, pois sua produção de categorias, métodos e teorias específicas é incipiente e frágil; de sua parte, para crescer e estabelecer-se, deve continuar, sim, utilizando os instrumentos teórico-metodológicos que a experiente Filosofia lhe proporciona, mas deve, também, avançar na criação de elementos científicos que lhe sejam próprios e significativos.

EP: $O$ que considera como sendo legitimamente uma "problemática educacional"? Quais são os problemas educacionais mais urgentes?

Pucci: São muitos os problemas educacionais urgentes na contemporaneidade. Cito alguns deles: o baixo salário dos docentes da educação básica, que os leva a aperfeiçoarem-se por meio de um mestrado profissional (com bolsa acrescida a seu salário) para, depois de formados, abandonarem a educação básica, buscando ganhar um pouco mais em uma faculdade particular; a violência que atinge a sociedade como um todo, por reduzir as relações sociais a relações de troca, e que, cada vez mais, invade o interior das escolas, as salas de aulas, apavorando e decepcionando os docentes; a dificuldade que os alunos do ensino fundamental e médio têm para ler e analisar um texto, para pensar e refletir, para expressar suas ideias em forma de um juízo claro - percebemos, frequentemente, esse problema nas redações de alunos que ingressam na universidade e até de mestrandos em seus projetos de dissertações -; o princípio do pragmatismo que caracteriza o ethos de nossa sociedade informatizada, que, ao mesmo tempo em que nos acumula de trabalho, nos rouba o tempo do ócio e nos prejudica sensivelmente nas atividades que exigem tempo, reflexão, paciência. Benjamin já percebia, à sua época, o predomínio da vivência em detrimento da experiência. Mas penso que o principal desafio para a educação nos dias de hoje é, em tempos de informatização que performa todas as atividades educativas, os docentes perceberem que estamos vivendo uma nova realidade, e que é preciso utilizar-se do potencial criativo da era digital em nossas experiências de ensino e pesquisa, bem como aprender a lidar com nossos educandos, sujeitos ativos e passivos das consequências desse novo modus vivendi; por enquanto, temos apenas aprendido a questionar os problemas daí resultantes; não tivemos ainda condições ou predisposições de dialogar criticamente com essa nova realidade, conhecê-la por dentro e incorporar sua incrível potencialidade a favor da formação. 
EP: Como analisa o debate entre educação e ensino e a tendência de querer subordinar a educação às questões de ensino?

Pucci: É um problema que acompanha, há muito tempo, minhas atividades acadêmicas. Quando ingressei na Unimep como docente, nossa tensão com os coordenadores de cursos de licenciatura e, sobretudo, de bacharelado era manter o número de aulas das disciplinas pedagógicas e de fundamentação em seus cursos. Eles não viam a necessidade de essas disciplinas desenvolverem seu trabalho formativo; queriam aumentar o número de aulas das disciplinas específicas do curso. Hoje, as atividades docentes desenvolvidas sob o rótulo de formação continuada, oferecida aos docentes da educação básica, caminham na direção de reduzir a educação ao ensino. É usual a expressão "ensino básico" no lugar de "educação básica". Essa mesma tendência fica clara nos chamados mestrados profissionais e nos mestrados a distância. O Programa de Mestrado Profissional stricto sensu em Matemática (Profmat) da Rede Nacional, criado pela Capes, em 2010, vinculado ao Sistema Universidade Aberta do Brasil (UAB) e coordenado pela Sociedade Brasileira de Matemática (SBM), é uma manifestação desse novo espírito dos tempos. Desenvolve-se na modalidade semipresencial e visa a atender professores de Matemática em exercício na educação básica, especialmente na escola pública, como forma de aprimorar a formação profissional, com ênfase no domínio aprofundado de conteúdo matemático. O Profmat já conta, em 2013, com a participação de 71 Instituições de Educação Superior (70 são IES federais). Os discentes ganham bolsa da Capes, que se soma ao seu salário de professor. Se, de um lado, poderão obter um conhecimento mais sólido em matemática para resolver os problemas de ordem prática, por outro lado, outros elementos qualitativos de sua formação são secundarizados: seu orientador pode ser um professor mestre, portanto alguém sem experiência consolidada em pesquisa; sua dissertação pode ser desenvolvida em equipe; seu objeto de estudo no trabalho final do curso se reduz a questões matemáticas. A pergunta que se faz ao Profmat poderia ser assim expressa: é possível enfrentar problemas da prática profissional sem a ajuda das disciplinas das áreas das ciências humanas que podem fornecer contribuições teórico-metodológicas para pensar, analisar, interpretar e buscar elementos adequados para a solução dos problemas que a experiência do magistério impõe? $\mathrm{O}$ ensino é um aspecto fundamental da educação, mas não absoluto. Eu, como estudioso da teoria crítica da sociedade, que analiso o processo educativo no contexto da Bildung, da formação humana, não posso deixar de me contrapor a um processo semiformativo que absolutiza uma das dimensões educativas e esquece-se das outras. Hipostasia-se a integração, o pragmatismo; desconsidera-se a crítica, a autonomia. Adorno, no ensaio "Teoria da 
semiformação", problematiza radicalmente esse pressuposto: "Quando o campo de forças a que chamamos formação se congela em categorias fixas - sejam elas do espírito ou da natureza, de transcendência ou de acomodação - cada uma delas, isolada, se coloca em contradição com seu sentido, fortalece a ideologia e promove uma formação regressiva".

EP: O que isso significa para a formação de novas gerações?

Pucci: Em tempos de tecnologias digitais, que cada vez mais nos absorvem, nos roubam tempo e nos fazem trabalhar intensivamente; nos dias dos smartphones, dos Instagrans, do You Tube, em que as informações vão ao infinito e é necessário ser rápido para captar os acontecimentos e fragmentário para expressá-los; em que é preciso ser cada vez mais prático nos estudos, na formação, nas especializações, novos e desafiantes problemas são colocados para os educadores. Como formar as novas gerações, plenamente integradas na vida digital, que trabalha 0 tempo todo com imagens e não conseguem utilizar adequadamente os conceitos? São os desafios que os docentes da educação básica enfrentam no dia a dia, com os adolescentes e com os jovens; são as questões que também se colocam para os docentes da pós-graduação, que orientam dissertações de docentes da educação básica. É preciso continuar ensinando e apoiando-se nos clássicos; é preciso buscar subsídios teórico-metodológicos na fenomenologia, no materialismo histórico, na teoria crítica da sociedade. Mas não podemos ensinar generalidades, nem pesquisar apenas fundamentos epistemológicos, quando as tecnologias digitais, que entram intempestivamente nas salas de aula da educação básica e nos estudos de nossos orientandos, estão desenvolvendo uma nova maneira de ver o mundo, de senti-lo, de pensá-lo, de expressá-lo.

EP: Considera um falso debate o tema da formação cultural versus formação profissional? Por quê?

Pucci: Analisando o debate a partir da teoria que orienta meus estudos e pesquisas, diria, sim, que ele é falso, pois não é possível desenvolver uma autêntica formação profissional sem a formação cultural do indivíduo. Giacoia Junior, em diálogo com Adorno, caracteriza bem a tensão e a complementação entre esses dois temas. Para ele, a formação cultural, a Bildung, pode ser entendida como "formação espiritual e interna, aperfeiçoamento, cultivo espiritual, cultura". Pessoas cultivadas, bem formadas, em sentido próprio, são aquelas que têm "horizonte" e "sensibilidade espiritual". Para tanto, exige-se delas "capacidade de reflexão, espírito crítico, faculdade de julgar, integração da multiplicidade dos saberes específicos na unidade de um gosto, estilo, graça, juízo, senso de valor" (2004). Por outro lado, 
considerando o debate a partir da Capes, dos cursos de formação continuada, dos programas de mestrado profissional ou a distância, o debate do tema da formação cultural versus formação profissional é verdadeiro, real, acontece, e é preciso ficar atento a ele e combatê-lo com nossas pesquisas e reflexões.

\section{EP: Como a filosofia da educação pode enfrentá-lo reflexivamente?}

Pucci: Colocando-o como objeto de suas pesquisas, de seus congressos, de seus debates. A Capes, dirigida hegemonicamente pelas áreas das ciências naturais, biológicas e tecnológicas, ao priorizar, em sua política de estado, a formação profissional dos docentes da educação básica, julga que, com isso, está contribuindo significativamente para a educação de nossas crianças, adolescentes e jovens. É preciso refletir sobre essas questões: será que, ao concretizar essa política de prioridade, por meio das bolsas aos docentes e do ensino profissionalizante, estará verdadeiramente contribuindo para sanar os problemas da educação básica, ou intensificando-os ainda mais? A reponsabilidade social da filosofia da educação é refletir radicalmente sobre as questões educacionais de seu momento histórico. Penso que o GT 17, da ANPEd, de Filosofia da Educação, ao priorizar, desde 2006, o tema da formação em suas reuniões na referida Associação, está trazendo uma contribuição importante nessa direção. Mas não basta.

Termino esta entrevista agradecendo à Comissão Editorial da Revista Espaço Pedagógico, particularmente ao colega e amigo Claudio A. Dalbosco, pela oportunidade para expressar ideias e relatar um pouco de minhas experiências. Espero que possam, de uma maneira ou de outra, provocar os leitores.

Piracicaba, outubro de 2013

Prof. Dr. Bruno Pucci

\section{Notas}

\footnotetext{
A coleta e a sistematização das informações presentes nesta edição da seção Diálogos com Educadores foram realizadas pelo Prof. Dr. Cláudio Almir Dalbosco, integrante do Programa de Pós-Graduação em Educação - Mestrado e Doutorado, da Universidade de Passo Fundo - RS.
} 